\title{
A Comparison of Effect of Semi Fowler's and Side Lying Position on Pulmonary Functions and Oxygen Saturation in Bedridden Patients
}

\author{
Pooja Patel ${ }^{1}$, Sweety Shah ${ }^{2}$ \\ ${ }^{1}$ Post-Graduate Student, SBB College of Physiotherapy, VSGH Hospital, Ahmedabad, Gujarat. \\ ${ }^{2} \mathrm{Ph} . \mathrm{D}$. MPT, SBB College of Physiotherapy, VSGH Hospital, Ahmedabad, Gujarat.
}

Corresponding Author: Pooja Patel

\begin{abstract}
Background: Body positioning is prescribed to optimize cardiopulmonary functions. Positioning helps to improve lung function and oxygen saturation in patients who are bedridden for longer duration. The aim of the present study is comparing semi fowler's position to side lying position (right and left side lying).

Method: Thirty bedridden subjects who were haemodynamically stable were included in the study. Out of them three groups were made in which first group was given semi fowler's position, second group was given left side lying and third group was given right side lying position. Patients have to maintain this position for 30 minutes.

Outcome measure: $\mathrm{FVC}, \mathrm{FEV}_{1}, \mathrm{RR}$ and $\mathrm{SPO}_{2}$ were taken before and after positioning which are objective measure of lung function and oxygen saturation respectively. Parameters were compared before and after positioning and between groups by non-parametric tests.

Result: shows significant difference between before and after within groups. When each of these sides lying position were compared to semi fowler's positions, semi fowler's position was found to be more effective in improving pulmonary functions and oxygen saturation.
\end{abstract}

Keywords: Semi Fowler's, Side Lying, Positioning, Pulmonary Functions, Oxygen Saturation.

\section{INTRODUCTION}

Therapeutic body positioning is different from routine body positioning which is prescribed to optimize cardiopulmonary function and oxygen transport in bedridden subjects. Body position stimulates normal physiological effect of gravity and position change in oxygen transport and lung volume. ${ }^{11]}$ This is very important in bed ridden patients. The distribution of ventilation and perfusion \& V/Q mismatch in the lungs are influenced primarily by gravity and therefore also by body positioning. Manipulating body position can alter determinants of ventilation, perfusion and pulmonary functions. Semi fowler's position is a variant of upright position in which head of bed is elevated to 30 to 45 degrees [2]. The side lying position is preferred more than the supine position for bedridden patients. Side lying position attenuated anterior-posterior expansion of transverse excursion of the dependent chest wall. FVC is maximum volume of air that can be exhaled out of the lung as forcefully as possible following maximum inspiration. Patients were asked to sit on bedside with support and take deep inspiration. A clip is placed over patients nose and patients exhales forcefully for $6 \mathrm{sec}$ in mouthpiece by sealing their lips tightly over the mouthpiece. $\mathrm{FEV}_{1}$ measures volume of air exhaled in first second of FVC ${ }^{[3]}$. Normal 
individuals can exhale $75 \%$ of vital capacity in first second of exhalation. $\mathrm{SpO}_{2}$ was measured with pulse oximeter. The infrared sensor of a pulse oximeter worn on the finger, toes or earlobe which detects amount of oxygen saturating haemoglobin by interpreting the density of the blood flow through the body part with the probe. Respiratory rate was measured per minute [4].

The need of present study is to provide insight about short term effect of positioning on pulmonary functions and provide baseline for rehabilitation of bedridden patients. So the aim of present study is to see effects of semi fowler's positioning and side lying positions on pulmonary functions and oxygen saturation in hemodynamically stable bedridden patients.

\section{MATERIALS AND METHODOLOGY Procedure:}

Observational study design was used to compare effects of positioning between semi fowler's and side lying positions. 30 patients were included in the study.

Inclusion criteria: Stable bedridden patients, male and female both, age between 15- 85 years.

Exclusion criteria: Patients with cerebral oedema, head injuries and neurosurgery, chest $\mathrm{x}$-ray showing pleural effusion, pneumothorax or atelectasis and severe hemodynamically instability.

Outcome measures: FVC (Forced vital capacity), $\mathrm{FEV}_{1}$ (forced expiratory volume in one sec), RR (respiratory rate), $\mathrm{SpO}_{2}$ (oxygen saturation).

Thirty patients were divided into three groups. 10 patients were given Semi Fowler's position (group A), 10 patients Right side lying (group B) and 10 patients were given Left side lying position (group C). Patients were given respective positions and maintained position for 30 minutes. All the parameters were recorded before and after giving positions. All readings were taken for 3 times and average of readings was taken into consideration. Before giving therapeutic positioning patient should be in supine position two hours priorly to eliminate bias in results.

Portable spirometer was used to measure FVC, $\mathrm{FEV}_{1}$. Oxygen saturation was measured by pulse oximeter and RR was measured manually. Initially patient was given supine position and parameters before giving positioning were recorded. Semi fowler's positions was given to patient be lifting the bed on head side up to 45 degrees. Side lying was achieved by turning patient to left and right supine side lying. Side lying was obtained by drawing the imaginary line from head of the humerus at an angle to the horizontal to obtain a 90 degree angle. Head supported by pillow, both arms will be fixed anteriorly and pillow was inserted between knees. Patients maintained these positioning and parameters were collected after 30 minutes.

\section{STATISTICAL ANALYSIS}

This study was conducted to compare semi fowler's position with any of the side lying position in bedridden patients for measuring pulmonary functions and oxygen saturation.

Statistical analysis was done using SPSS software version 16 and Microsoft Excel 2017 was used to generate tables.

Confidence level was kept $95 \%$ with level of significance kept at 0.05. Before applying statistical tests, the data was screened for normal distribution. FVC, $\mathrm{FEV}_{1}, \mathrm{RR}$ and $\mathrm{SPO}_{2}$ was not normally distributed, so nonparametric tests were applied for comparing pre and post values of individual tests and comparing one test with other.

\section{RESULTS}

Total 30 subjects participated in the study. Mean age $=55.19 \pm 17.31$. There was significant improvement in FVC \& $\mathrm{FEV}_{1}$, $\mathrm{SpO}_{2}$ \& RR after giving semi fowler's position. There was no significant change seen in FVC, $\mathrm{FEV}_{1}, \mathrm{SpO}_{2} \& \mathrm{RR}$ in both left and right side lying. Comparing semi Fowler's position to each of these side 
Pooja Patel et.al. A comparison of effect of semi fowler's and side lying position on pulmonary functions and oxygen saturation in bedridden patients.

lying positions, semi Fowler's positioning

$\mathrm{FEV}_{1}, \mathrm{RR}$ and $\mathrm{SpO}_{2}$.

found to be better in improving FVC,

TABLE 1: FVC Before and After Giving Positioning:

\begin{tabular}{|l|l|l|l|l|l|}
\hline POSITION & Pre Mean \pm SD & Post Mean \pm SD & Z value & P value & Interpretation \\
\hline Semi fowler's & $1.132 \pm 0.088$ & $1.474 \pm 0.094$ & -2.805 & 0.005 & Significant \\
\hline RT side lying & $1.108 \pm 0.116$ & $1.13 \pm 0.150$ & -0.299 & 0.765 & Not significant \\
\hline LT side lying & $1.128 \pm 0.09$ & $1.129 \pm 0.08$ & -0.299 & 0.765 & Not significant \\
\hline
\end{tabular}

TABLE 2: FEV $V_{1}$ Before and After Giving Positioning:

\begin{tabular}{|l|l|l|l|l|l|}
\hline POSITION & Pre Mean \pm SD & Post Mean \pm SD & Z value & P value & Interpretation \\
\hline Semi fowler's & $0.937 \pm 0.053$ & $1.23 \pm 0.100$ & -2.812 & 0.005 & Significant \\
\hline RT side lying & $0.83 \pm 0.06$ & $0.924 \pm 0.09$ & -2.345 & 0.190 & Not significant \\
\hline LT side lying & $0.878 \pm 0.08$ & $0.861 \pm 0.040$ & -2.354 & 0.120 & Not significant \\
\hline
\end{tabular}

TABLE 3: RR Before and After Giving Positioning:

\begin{tabular}{|l|l|l|l|l|l|}
\hline POSITION & Pre Mean \pm SD & Post Mean \pm SD & Z value & P value & Interpretation \\
\hline Semi fowler's & $20.6 \pm 2.01$ & $19 \pm 1.63$ & -2.549 & 0.010 & Significant \\
\hline RT side lying & $19.3 \pm 1.15$ & $20 \pm 1.24$ & -1.841 & 0.066 & Not significant \\
\hline LT side lying & $20.6 \pm 2.79$ & $20.1 \pm 2.68$ & -1.81 & 0.060 & Not significant \\
\hline
\end{tabular}

TABLE 4: $\mathrm{SPO}_{2}$ Before and After Giving Positioning:

\begin{tabular}{|l|l|l|l|l|l|}
\hline POSITION & Pre Mean \pm SD & Post Mean \pm SD & Z value & P value & Interpretation \\
\hline Semi fowler's & $95.9 \pm 1.19$ & $99.2 \pm 0.63$ & -2.831 & 0.005 & Significant \\
\hline RT side lying & $96.2 \pm 1.39$ & $96.7 \pm 1.82$ & -1.890 & 0.059 & Not significant \\
\hline LT side lying & $96.6 \pm 1.77$ & $96.8 \pm 1.93$ & -1.980 & 0.055 & Not significant \\
\hline
\end{tabular}

TABLE 5: Semi Fowler's versus RT Side Lying:

\begin{tabular}{|l|l|l|}
\hline & P value & significance \\
\hline FVC & 0.001 & Significant \\
\hline FEV & 0.000 & Significant \\
\hline RR & 0.152 & Not significant \\
\hline SPO $_{\mathbf{2}}$ & 0.001 & Significant \\
\hline
\end{tabular}

TABLE 6: Semi Fowler's versus LT Side Lying:

\begin{tabular}{|l|l|l|}
\hline & P value & significance \\
\hline FVC & 0.001 & Significant \\
\hline FEV & 0.000 & Significant \\
\hline RR & 0.155 & Not significant \\
\hline SPO $_{\mathbf{2}}$ & 0.000 & Significant \\
\hline
\end{tabular}

TABLE 7: RT Side Lying versus LT Side Lying:

\begin{tabular}{|l|l|l|}
\hline & P value & Significance \\
\hline FVC & 1.000 & Not significant \\
\hline FEV & 1.000 & Not significant \\
\hline RR & 1.000 & Not significant \\
\hline SPO $_{\mathbf{2}}$ & 1.000 & Not significant \\
\hline
\end{tabular}

\section{DISCUSSION}

The present study was conducted with the aim of comparing different therapeutic positioning in bedridden patients, there were no adverse events found. Total 30 subjects were included in the study. There was significant improvement in $\mathrm{FVC}, \mathrm{FEV}_{1}, \mathrm{RR}$ and $\mathrm{SpO}_{2}$ after giving semi fowler's positioning.

In supine positioning bodyweight restrict free movement of ribcage which decreases lung volumes and capacities. Residual volume of the lung drops in bedridden patients, potentially increasing the risk of portions of lung collapse. There is decrease in FVC \& $\mathrm{FEV}_{1}$ due to combination of effect of airway obstruction, increased resistance and loss of elastic recoil as result of structural changes within the lungs. Compressing forces also affects the heart and cardiac output in supine position. Semi fowler's position is variant of upright position ${ }^{[5]}$.

When in upright position, the diameter of the main airways increases slightly. When a person is in upright, the vertical gravitational gradient is more, the anteroposterior diameter of the chest is greatest, and compression on heart and lungs are minimal ${ }^{[6]}$. The increase in spirometric values in semi fowler's position was attributed to descent of diaphragm for the extra volume of air inspired during forced vital capacity manoeuvre which had the highest lung volumes ${ }^{[7]}$.

Side lying position there is increase in airflow resistance and a greater excursion on diaphragm as diaphragm ascends upwards ${ }^{[8]}$. Compared with the semi fowler' FVC and $\mathrm{FEV}_{1}$ are reduced in left and right side lying because of altered lung geometry with position change and 
reduction in vertical diameter of each lung in side lying ${ }^{[9]}$.Manning et al conducted study to find effects of positioning on lung functions and found that FVC and $\mathrm{FEV}_{1}$ are reduced comparably for right and left side lying positions compared with sitting position. In semi fowler's position $\mathrm{SpO}_{2}$ is better than in supine ${ }^{[10]}$. Blood flow and ventilation is significantly greater to the dependent lung than to nondependent lung $^{[11]}$.

Good V/Q matching at the dependent lungs results in the adequate oxygenation in the awake patient who is breathing spontaneously. The related changes may be due to increase in intrathoracic blood volume due to gravitational facilitation of venous return and upward displacement of diaphragm caused by abdominal encroachment. The probable reason behind semi fowler's position been more effective is gravity, force length variation observed in respiratory muscles according to several posture of human body ${ }^{[12]}$.

The FRC in side lying falls between that in upright and supine position. Compared with supine in side lying, compliance is increased, resistance is reduced, and the work of breathing is reduced, whereas these measures are reversed when side lying is compared to upright position. That's why semi Fowler's position proved to be more effective than side lying ${ }^{[10]}$.

Limitation of the study is that duration of the treatment for therapeutic position was short. Patients were not divided according to their conditions and age. Future studies can be done by dividing patients into different group according to severity of the diseases and age. Studies can be done for comparing other therapeutic positioning and to see effects on other parameters of lung functions, DLCO, heart functions etc.

\section{CONCLUSION}

Comparing semi fowler's position to each of these side lying positions, semi fowler's position was found better in improving $\mathrm{FVC} \& \mathrm{FEV}_{1}$ in bedridden patients.

\section{ACKNOWLEDGEMENT}

We are thankful to all the subjects who participated in our study. I am thankful to my parents, colleagues and all the staff members of the SBB college of Physiotherapy for their support and motivation. Special thanks to my guide Dr. Sweety Shah for always supporting, motivating and helping me throughout the study.

\section{Conflict of Interest: None}

\section{Source of Funding: None}

\section{Ethical Approval: Approved}

\section{REFERENCES}

1. Elizaberth Dean et al, Effect of body positioning on pulmonary functions: 2014:;(5)

2. Mark C Rogers"Textbook of Peadiatric Intensive Care", 5thedition.

3. Donna L Frownfelter, Elizabeth Dean "Cardiovascular and pulmonary physiotherapy" 4thedition, published by Mosboy 1996,

4. David W. Chang,"Clinical Application of Mechanical Ventilation" (2 nd edition); Georgia,

5. William E.De Turek, Lawrence P. Cahalin,"Cardiovascular and pulmonary physical therapy- an evidence based approach" 3rdedition,Mc Grow Hill Publication

6. Fiona manning. Elizabeth Dean Effects of sidelying on lung function in older individuals:;2013

7. Ben-Dov I, Zlobinski R, Segel MJ, Gaides M, Shulimzon T, Zeilig G. Ventilatory response to hypercapnia in $\mathrm{C}(5-8)$ chronic tetraplegia: the effect of posture. Arch Phys Med Rehabil. 2009

8. Vilke GM, Chan TC, Neuman T, Clausen JL. Spirometry in normal subjects in sitting, prone, and supine positions. Respir Care. 2000

9. Ceridon ML, Morris NR, Olson TP, Lalande S, Johnson BD. Effect of supine posture on 
Pooja Patel et.al. A comparison of effect of semi fowler's and side lying position on pulmonary functions and oxygen saturation in bedridden patients.

airway blood flow and pulmonary function in stable heart failure. Respir Physiol Neurobiol. 2011

10. 4 Lewis ML, Christianson LC. Behavior of the human pulmonary circulation during head-up tilt. J Appl Physiol. 1978

11. Respiratory physiology, A Clinical Approach, Schwartzstein \& Parke

12. Dirk Pappert, MD; Rolf Rossaint, MD; Klaus Slama, MD "Influence of Positioning on Ventilation-Perfusion Relationships in Severe Adult Respiratory Distress Syndrome", Chest 1994

How to cite this article: Patel P, Shah S. A comparison of effect of semi fowler's and side lying position on pulmonary functions and oxygen saturation in bedridden patients. Int $J$ Health Sci Res. 2021; 11(5): 53-57. DOI: https://doi.org/10.52403/ijhsr.20210507 